\title{
Microscopic Deformation Behavior Observation of Lamellar Pearlite during Plastic Deformation*
}

\author{
Yu SAKODA**, Suguru KASHIWAGI***, \\ Shigeru HAMADA **** and Hiroshi NOGUCHI**** \\ **Graduate School of Engineering, Kyushu University, \\ 744, Moto-oka, Nishi-ku, Fukuoka-shi, Fukuoka, 819-0395, Japan \\ Email: te207311@s.kyushu-u.ac.jp \\ ***School of Engineering, Kyushu University \\ ${ }^{* * * *}$ Faculty of Engineering, Kyushu University
}

\begin{abstract}
The fatigue ratio of lamellar pearlite steel used for railroad rails is lower than the ratio of general steels. The reason for this has not yet been clarified. It is reported that the direction of the lamellar microstructure in the lamellar pearlite steel affects the fatigue characteristics. In order to clarify the microscopic deformation behavior of the lamellar microstructure considered to affect the fatigue characteristics, static tensile tests of the lamellar pearlite steel were conducted. Using the plastic replica technique, the microscopic deformation behavior i.e. the initiation and propagation of microcracks was observed. Based on the experimental results, transgranular cracks and intergranular cracks were observed. The obtained main results are as follows.

(1) The transgranular crack originated in the discontinuous area in the lamellar pearlite microstructure. The transgranular crack initiates in a 45 degree direction to the axis of tension. The transgranular crack does not break through the grain boundary.

(2) The intergranular crack does not propagate, but opens.

(3) The difference in the material characteristics affected by heat treatment is the total strain of the crack initiation.
\end{abstract}

Key words: Lamellar Pearlite, Transgranular Crack, Intergranular Crack, Crack Initiation

\section{Introduction}

The main reason of breakage failure of industrial products is fatigue failure. For railroad rails, fatigue breakdown is the main reason. In order to prolong the life or maintenance interval for railroad rail steel, it is necessary to clarify the fatigue strength and mechanism of fatigue failure of such steels.

Urashima et al. ${ }^{(1)}$ performed a rotating bending fatigue test of railroad rails. Based on their result, the direction of the lamellar microstructure in railroad rail steel, which has a lamellar pearlite microstructure, affected the on fatigue crack initiation. Fatigue ratio of lamellar pearlite steel is lower than that of general steels, but the reason is not clarified. The author suggested treating the lamellar pearlite steel which is a complex material formed from a ferrite layer and cementite layer.

Murakami et al. ${ }^{(2)}$ performed static tensile tests of a carbon steel round bar, type $\mathrm{S} 45 \mathrm{C}$, 
which has a pearlite microstructure $(0.46 \% \mathrm{C}$, diameter $22 \mathrm{~mm})$ and observed a continuous microcrack initiation on the specimen's surface. The author theorized that if a microcrack on a statically deformed lamellar pearlite steel initiates at a strain lower than that result, the microcrack has an effect on lowering the fatigue ratio of the lamellar pearlite steel.

In order to clarify the microscopic deformation behavior of the lamellar microstructure considered to affect the fatigue characteristics, static tensile tests of the lamellar pearlite steel were performed. Using the plastic replica technique, the microscopic deformation behavior i.e. the initiation and propagation of microcracks was observed.

\section{Experimental procedures}

\subsection{Material and specimen}

The test sample for this study was lamellar pearlite steel used for railroad rails. Table 1 shows the chemical composition of this material. The materials used for the static tensile test included 3 kinds of lamellar pearlite steels, which have a different hardness, depending on heat treatment. Table 2 shows the mechanical properties of these materials. The carbon contents of these materials are $0.89 \%$ which is higher than that of eutectoid steel of $0.77 \%$. These materials are hypereutectoid steels. Figure 1 shows the optical microstructure of these materials. These materials have a lamellar pearlite microstructure. The spacing between the ferrite layer and cementite layer in the lamellar pearlite microstructure is different for each material. Material $\mathrm{C}$ has the widest spacing. Material $\mathrm{A}$ is the narrowest of these materials.

Table1 Chemical composition (mass $\%$ )

\begin{tabular}{c|c|c|c|c|c|c}
\hline $\mathrm{C}$ & $\mathrm{Si}$ & $\mathrm{Mn}$ & $\mathrm{P}$ & $\mathrm{S}$ & $\mathrm{Cr}$ & $\mathrm{N}$ \\
\hline 0.89 & 0.4 & 0.92 & 0.018 & 0.013 & 0.24 & 0.041 \\
\hline
\end{tabular}

Table2 Mechanical properties

\begin{tabular}{c|c|c|c}
\hline Material & $\sigma_{0.2}(\mathrm{MPa})$ & $\sigma_{\mathrm{B}}(\mathrm{MPa})$ & $\mathrm{HV}$ \\
\hline $\mathrm{A}$ & 873 & 1268 & 400 \\
\hline $\mathrm{B}$ & 764 & 1215 & 360 \\
\hline $\mathrm{C}$ & 671 & 1129 & 320 \\
\hline
\end{tabular}

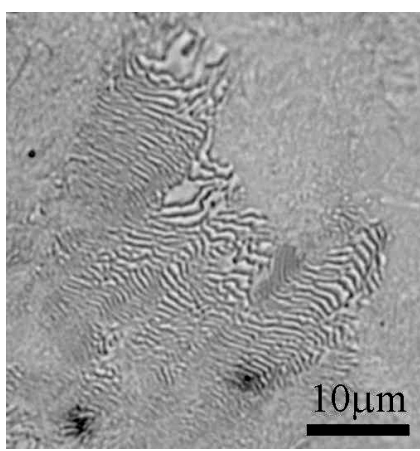

(a) Material A

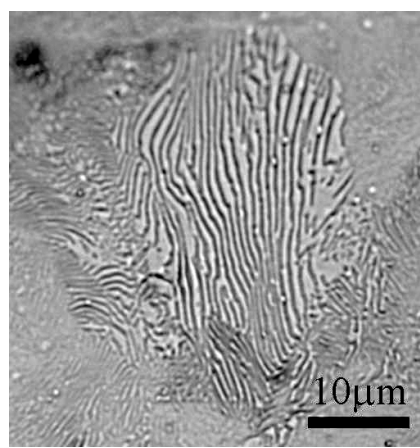

(b) Material B

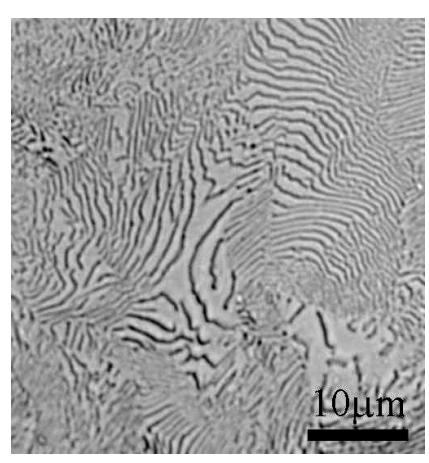

(c) Material C

Fig.1 Microstructure of rail steel

Table 3 Range of lamellar spacing

\begin{tabular}{|c|c|}
\hline Material & Lamellar spacing $(\mu \mathrm{m})$ \\
\hline A & $0.11 \sim 1.0$ \\
\hline B & $0.20 \sim 1.5$ \\
\hline C & $0.25 \sim 2.0$ \\
\hline
\end{tabular}




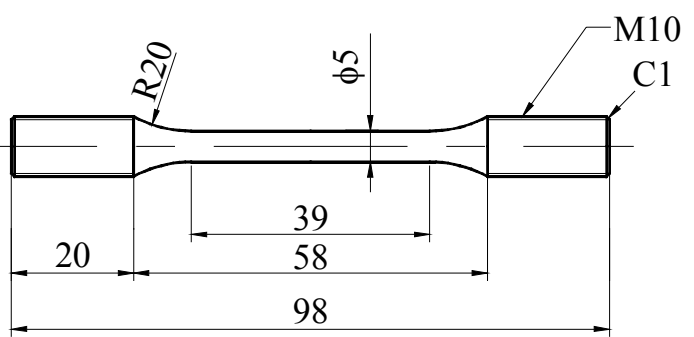

(a) Tensile specimen (type A)

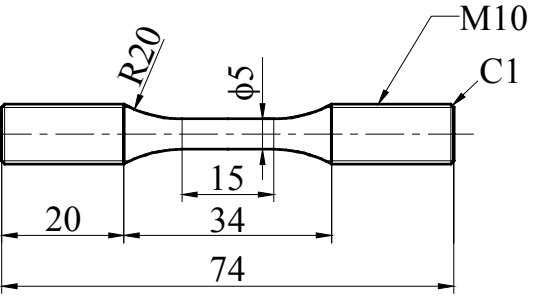

(b)Tensile specimen (type B)

Fig.2 Shapes and dimensions of specimen

Figure 2 shows the shapes and dimensions of the static tensile specimens. Table 3 shows the range of lamellar spacing. The specimens were mechanically-polished with \#2000 emery paper. The specimens were then electropolished.

\subsection{Static tensile test method}

The static tensile tests were performed at room temperature. The stroke speed of the test machine was $0.5 \mathrm{~mm} / \mathrm{min}$. The stress-strain curve was obtained by carrying out the static tensile test using the specimen type A which was formed on the basis of JIS Z 2201. The total strain was measured by an extensometer. Figure 3 shows the stress-strain curve. The specimen type B has a shorter length than the specimen type A in order to observe entire test area during the static tensile test. Using the plastic replica technique, the microscopic deformation behavior was continuously observed on test sample. During the elastic deformation, the replica was obtained by maintaining the load and during plastic deformation, the replica was obtained by interrupting the loading. Figure 3 the $\mathrm{x}$ indications show the point of observation. The replica gold ion sputtered and observed with optical microscope.

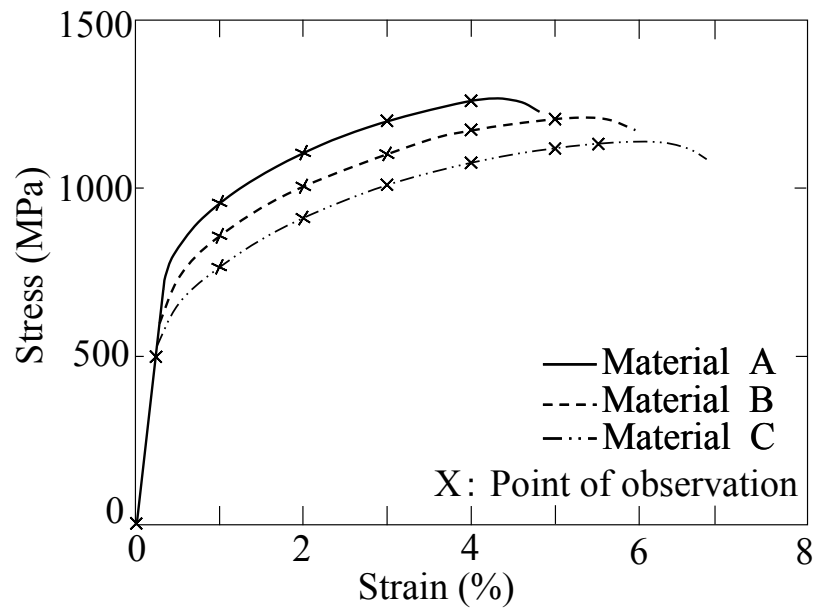

Fig.3 Stress-Strain Curve

\section{Results and Discussion}

Using the plastic replica technique, the initiation and propagation of surface microcracks on lamellar pearlite steel were observed. Takahashi et al. ${ }^{(3)(4)}$ performed similar observations of eutectoid steel. Based on the results, a concept of the pearlite block was proposed as an area which has a constant crystallographic orientation of ferrite in the pearlite microstructure and has some pearlite colonies. The pearlite block is treated to be different from the austenite grain boundary. Figure 4 shows the microstructure observed 
using the optical microscope. We could not observe that the pearlite block was different from the austenite grain boundary. Therefore, in this report, the boundary observed in the lamellar pearlite microstructure was treated as the austenite grain boundary. Figures 5 and 6 show an example of microscopic deformation behavior. Two kinds of microcracks were observed in the materials. Those were transgranular cracks and intergranular cracks.

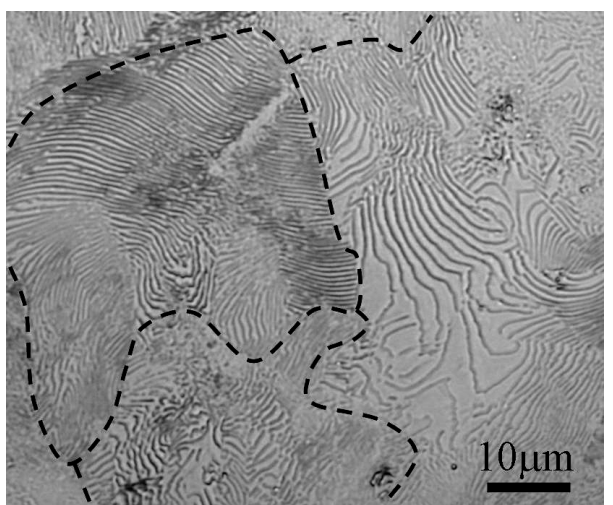

Fig.4 Optical microstructure of material C (Dashed line shows austenite grain boundary)

\subsection{Transgranular crack}

Figure 5 shows the propagation behavior example of the transgranular crack. The strain at which the microcrack initiated was different for each material. The transgranular crack in material $\mathrm{C}$ initiated at a total strain $\varepsilon_{\mathrm{t}}=3.0 \%$. The transgranular crack in material $\mathrm{A}$ and material $\mathrm{B}$ did not initiate at $\varepsilon_{\mathrm{t}}=3.0 \%$. However a number of transgranular cracks in material B were observed at $\varepsilon_{\mathrm{t}}=4.0 \%$, higher than that in material $\mathrm{A}$. Therefore, the granular crack in material B would initiate at a lower strain than that in material A. The reason why the strain at which the microcrack initiates was different for each material was due to the difference in the hardness of each material. Ueda et al. ${ }^{(5)}$ reported that high tensile strength railroad rail steel in which the spacing between the ferrite layer and cementite layer is refined contributes the prolonging the life of the railroad rail. Furthermore, it is said that the static strength increases as the spacing between the ferrite layer and cementite layer is refined ${ }^{(6)-(8)}$. Based on that report, the tensile strength would be enhanced by refining the spacing between the ferrite layer and cementite layer. The transgranular crack originated in the discontinuous area in the lamellar pearlite microstructure. The transgranular crack does not break through grain boundary. The reason for this is that when a transgranular crack breaks through the austenite grain boundary, the crack must propagate into the crystal grain which has a different crystal orientation. The crack propagation resistance then increases. Many transgranular crack initiations and propagations at a 45 degree direction to the axis of tension and in the vertical direction of the lamellar microstructure were observed as shown in Fig. 5. Therefore, the shear deformation would effect the static tensile crack initiation and propagation.

\subsection{Intergranular crack}

Figure 6 shows the crack opening behavior of an intergranular crack. The intergranular crack initiated in a $45 \sim 90$ degree direction to the axis of tension and through the austenite grain boundary. The intergranular crack in material A and material B initiated at $\varepsilon_{\mathrm{t}}=2.0 \%$. The intergranular crack in material $\mathrm{C}$ initiated at $\varepsilon_{\mathrm{t}}=3.0 \%$. The intergranular crack did not propagate and open during the strain increasing as shown in Fig. 6. The reason for this is that the crack propagation resistance increases when the intergranular crack propagates at the austenite grain boundary which produces a different direction for intergranular cracks. 
$\longleftrightarrow$ Axial direction

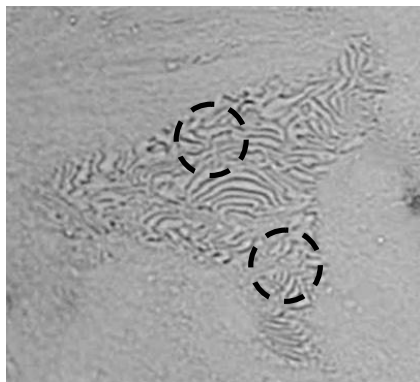

$\varepsilon_{\mathrm{t}}=0.0 \%$

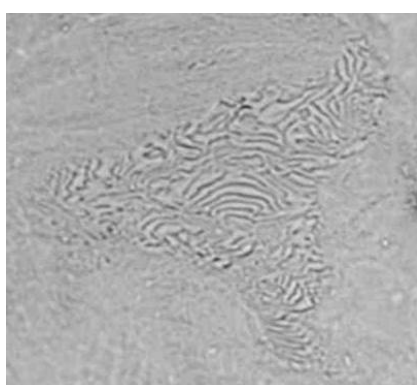

$\varepsilon_{\mathrm{t}}=3.0 \%$

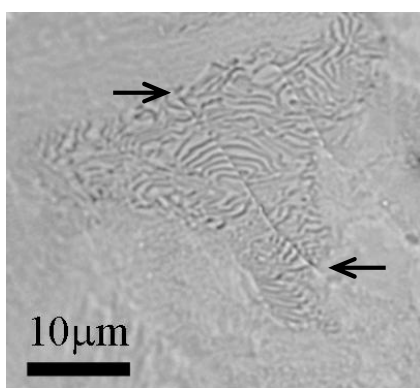

$\varepsilon_{\mathrm{t}}=4.0 \%$

(a) Material A

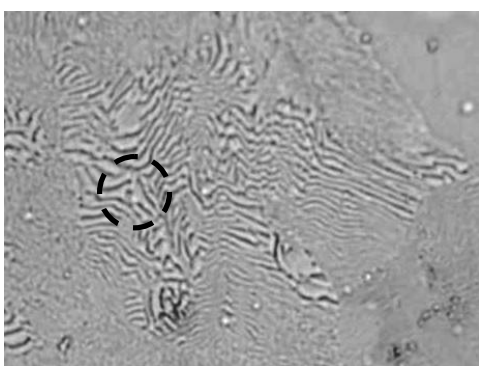

$\varepsilon_{\mathrm{t}}=0.0 \%$

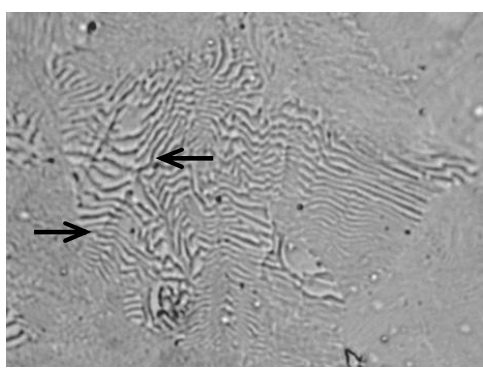

$\varepsilon_{\mathrm{t}}=4.0 \%$

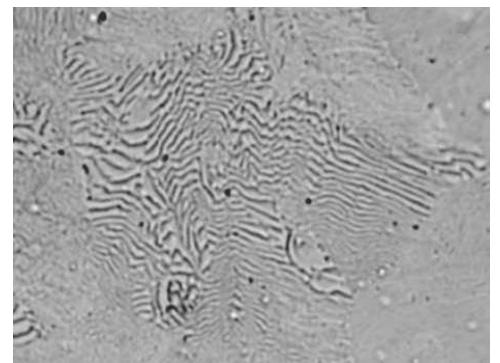

$\varepsilon_{\mathrm{t}}=3.0 \%$

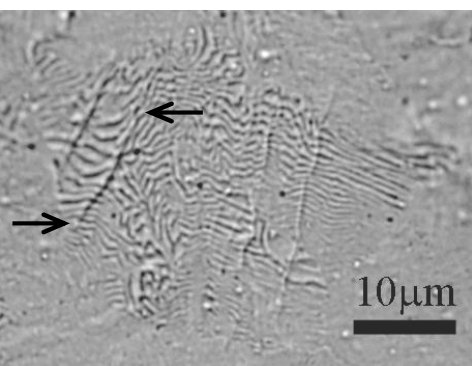

$\varepsilon_{\mathrm{t}}=5.0 \%$

(b) Material B

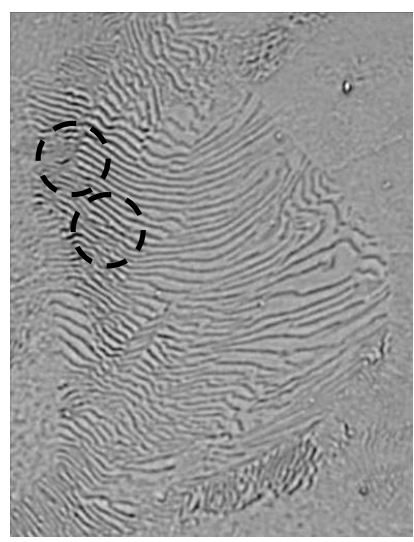

$\varepsilon_{\mathrm{t}}=0.0 \%$

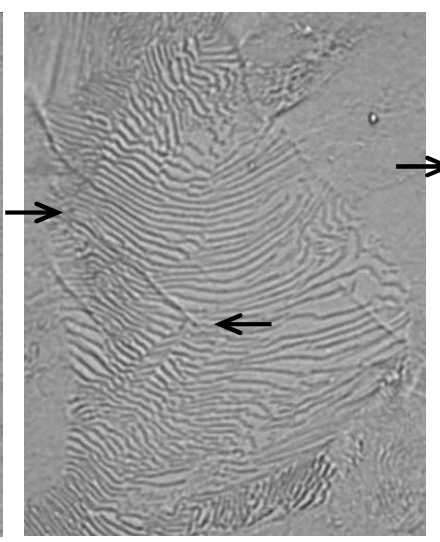

$\varepsilon_{\mathrm{t}}=3.0 \%$

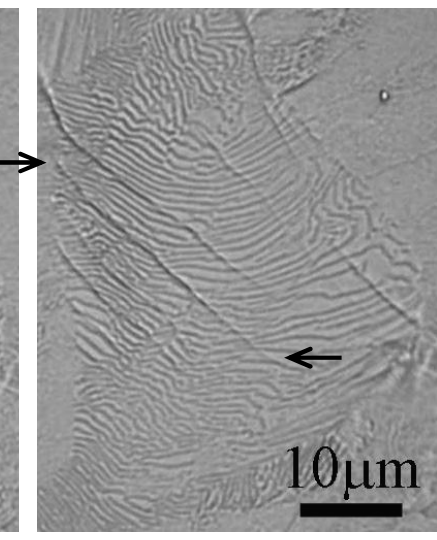

$\varepsilon_{\mathrm{t}}=4.0 \%$

(c) Material C

Fig.5 Propagation behavior of transgranular crack (Arrow shows crack tip, Dashed line shows the discontinuous area.) 


\subsection{Heat treatment effects}

One of heat treatment effects was that the strain at which the microcrack initiates was different for each material. Table 4 shows the results of our observations. Material A has the strongest crack initiation resistance of the three materials for transgranular cracking. Material $\mathrm{C}$ has the strongest crack initiation resistance of the three materials for intergranular cracking. Therefore, the strength of the austenite grain boundary would change depending on the heat treatment. We thought that if the lamellar pearlite steel was treated as a complex material, which is formed from ferrite and cementite layers, microcracks would initiate at a low strain. However, because the microcrack originated at a discontinuous area

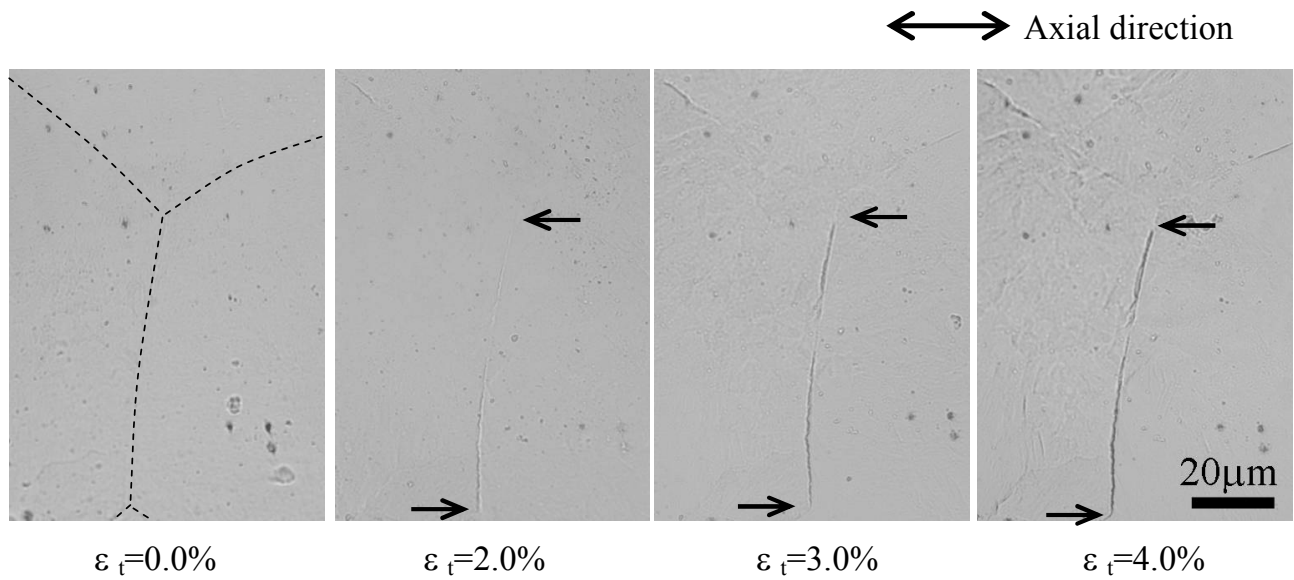

(a) Material $\mathrm{A}$

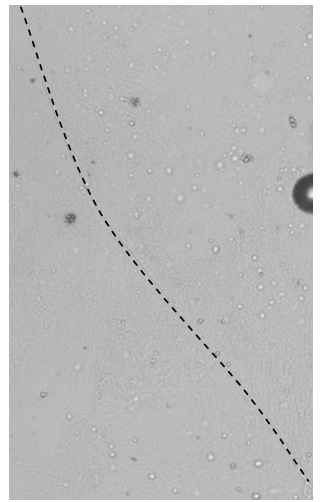

$\varepsilon_{\mathrm{t}}=0.0 \%$

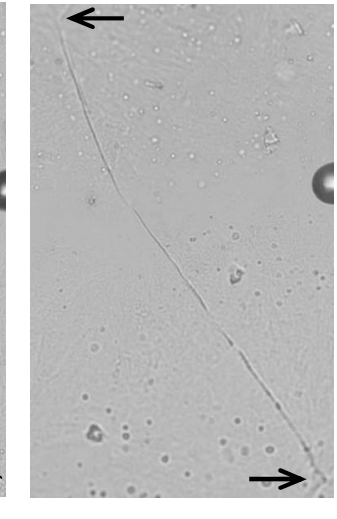

$\varepsilon_{\mathrm{t}}=2.0 \%$

(b) Material B

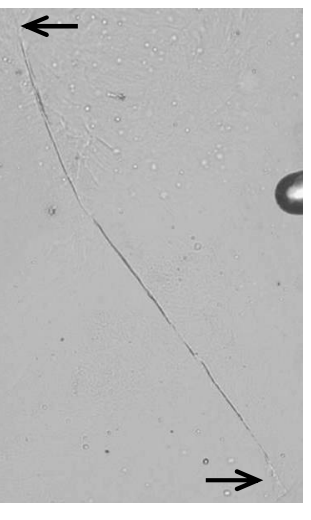

$\varepsilon_{\mathrm{t}}=3.0 \%$

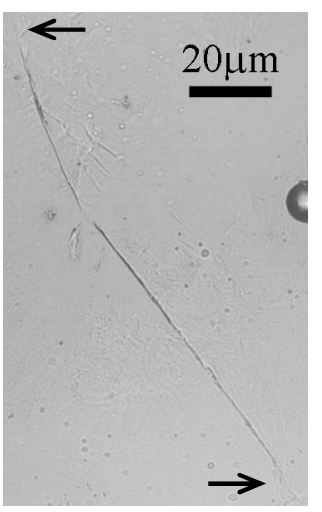

$\varepsilon_{\mathrm{t}}=4.0 \%$

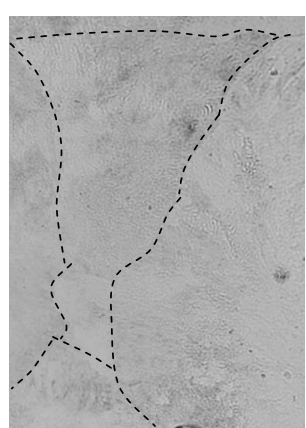

$\varepsilon_{\mathrm{t}}=0.0 \%$

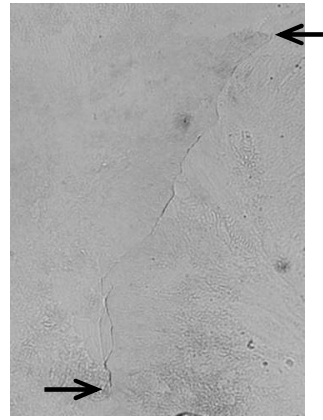

$\varepsilon_{\mathrm{t}}=3.0 \%$

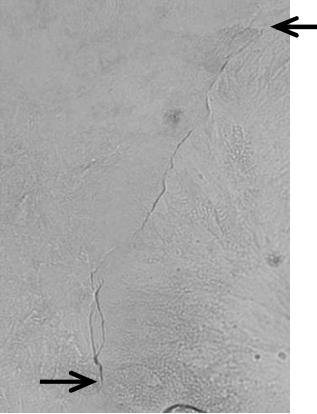

$\varepsilon_{\mathrm{t}}=4.0 \%$

(c) Material C

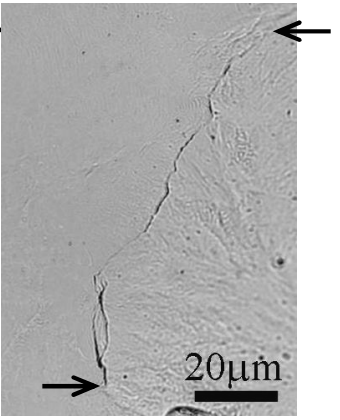

$\varepsilon_{\mathrm{t}}=5.0 \%$

Fig.6 Crack opening behavior of intergranular crack (Arrow shows crack tip, Dashed line shows austenite grain boundary) 
in the lamellar pearlite microstructure, the lamellar pearlite steel could not be treated as a simple complex material. The strain at which the microcrack initiated was similar to Murakami et al. ${ }^{(2)}$ results. The result that the transgranular crack initiates in a 45 degree direction to the axis of tension and does not break through the grain boundary is similar to the report that a slip band initiates at a 45 degree direction to the axis of tension during static failure and does not break through the pearlite block ${ }^{(3)}$. When compared the Urashima et al. report on fatigue cracking, this study agrees with the fact that the crack initiates in a 45 degree direction to the axis of tension. However, this study disagrees with the angle at which the crack initiates in a direction to the lamellar microstructure. Therefore, we are planning consider by fatigue testing in the near future.

Table 4 Observation result ( $\mathrm{N}$ shows no crack, I shows crack initiation)

\begin{tabular}{|c|c|c|c|c|c|c|c|}
\hline \multicolumn{2}{|c|}{ Total strain $\varepsilon_{\mathrm{t}}(\%)$} & 0.0 & 1.0 & 2.0 & 3.0 & 4.0 & 5.0 \\
\hline \multirow{4}{*}{$\begin{array}{c}\text { Transgranular } \\
\text { crack }\end{array}$} & Material A & $\mathrm{N}$ & $\mathrm{N}$ & $\mathrm{N}$ & $\mathrm{N}$ & $\mathrm{I}$ & - \\
\cline { 2 - 8 } & Material B & $\mathrm{N}$ & $\mathrm{N}$ & $\mathrm{N}$ & $\mathrm{N}$ & $\mathrm{I}$ & $\mathrm{I}$ \\
\cline { 2 - 8 } & Material C & $\mathrm{N}$ & $\mathrm{N}$ & $\mathrm{N}$ & $\mathrm{I}$ & $\mathrm{I}$ & $\mathrm{I}$ \\
\hline \multirow{4}{*}{$\begin{array}{c}\text { Intergranular } \\
\text { crack }\end{array}$} & Material A & $\mathrm{N}$ & $\mathrm{N}$ & $\mathrm{I}$ & $\mathrm{I}$ & $\mathrm{I}$ & - \\
\cline { 2 - 8 } & Material B & $\mathrm{N}$ & $\mathrm{N}$ & $\mathrm{I}$ & $\mathrm{I}$ & $\mathrm{I}$ & $\mathrm{I}$ \\
\cline { 2 - 8 } & Material C & $\mathrm{N}$ & $\mathrm{N}$ & $\mathrm{N}$ & $\mathrm{I}$ & $\mathrm{I}$ & $\mathrm{I}$ \\
\hline
\end{tabular}

\subsection{Fatigue Ratio}

By the observation, it is clarified that grain size transgranular and intergranular crack initiate but do not propagate during static tensile test. The authors presume the fatigue of lamellar pearlite steel as follow: The grain size crack initiate at initial stage of fatigue process, and the crack act as initial defect of the lamellar pearlite steel. Then the fatigue life of lamellar pearlite steel is equal to crack propagate life, and fatigue ratio of lamellar pearlite steel becomes lower than the ratio of general steels which have no initial defect.

In order to confirm the presumption, the authors try predicting the ratio of lamellar pearlite steel. The fatigue limit of metal which has defect is predicted by Murakami's equation $^{(9)}$. The equation is

$$
\sigma_{w}=\frac{1.43(H V+120)}{\sqrt{\text { area }}^{1 / 6}}
$$

where $\sigma_{\mathrm{w}}$ is fatigue limit $(\mathrm{MPa}), H V$ is Vickers hardness $\left(\mathrm{kg} / \mathrm{mm}^{2}\right)$ and $\sqrt{\text { area }}$ is defect size $(\mu \mathrm{m})$. By Eq.(1), the fatigue limit of the lamellar pearlite steel are predicted using the grain size $(\cong 20 \mu \mathrm{m})$ as $\sqrt{\text { area }}$. As the result, the predicted fatigue ratio are $0.34 \sim 0.36$ which show good agreement with the test result by Urashima et al. ${ }^{(1)}$

\section{Conclusion}

In order to clarify the microscopic deformation behavior of the lamellar microstructure considered to affect the fatigue characteristics, static tensile tests of lamellar pearlite steel were performed. Using the plastic replica technique, the microscopic deformation behavior was continuously observed on the test area in detail. The obtained results are as follows.

(1) The transgranular crack originated in the discontinuous area in the lamellar pearlite microstructure. The transgranular crack initiates in a 45 degree direction to the axis of tension. The transgranular crack does not break through the grain boundary.

(2) The intergranular crack does not propagate, but opens.

(3) The difference in the material characteristics affected by the heat treatment is the total strain during crack initiation. 
By the observation, the authors presume the fatigue of lamellar pearlite steel as follow: The grain size crack initiate at initial stage of fatigue process, and the crack act as initial defect. Then fatigue ratio of lamellar pearlite steel becomes lower than the ratio of general steels.

\section{References}

(1) Urashima, T. and Nishida, S., Fatigue Crack Initiation and Propagation Behavior and Fracture Surface of Eutectoid Steels, Journal of the Society of Materials Science, Japan, Vol.43, No.488 (1994), pp.515-521.

(2) Murakami, Y. and Miller, K.J., What is fatigue damage? A view point from the observation of low cycle fatigue process, International Journal of Fatigue, Vol.27 (2005), pp991-1005.

(3) Takahashi, T. Nagumo, M. and Asano, Y., Microstructures Dominating the Ductility of Eutectoid Pearlitic Steels, Journal of the Japan Institute of Metals,Vol.42, No.7(1978), pp.708-715.

(4) Takahashi, T. Nagumo, M. and Asano, Y., Crystallographic Features and Formation Processes of Pearlite Block, Journal of the Japan Institute of Metals, Vol.42, No.7 (1978), pp716-723.

(5) Ueda, S. Uchino, K. and Senuma, T., Influence of microstructure on rolling contact wear in high carbon steels, The journal of the Iron and Steel Institute of Japan, Vol.90, No.12 (2004), pp1023-1030.

(6) Tarui, T. Maruyama, N. Takahashi, J. Nishida, S. and Tashiro, H., Microstructure control and strengthening of high carbon steel wires, Nippon Steel Technical Report, No.381 (2004), pp.51-56.

(7) Daito, Y. Sano, N. Hamada, T. Takagi, S. and Hidaka, H., Relationship between microstructural charges and strength in heavily drawn Pearlitic wires, Current Advances in Materials and Processes, Vol.16, No.3 (2003), pp.494-497.

(8) Maehata, T. Hakano, M. and Ioka, H., Development of High Strength Steel Strand for Prestressed Concrete, Journal of the Society of Materials Science, Japan, Vol.56, No.8 (2007), pp.694-698.

(9) Murakami, Y., Metal fatigue: effects of small defects and nonmetallic inclusions, (2002), p.61, Elsevier, Oxford, Boston. 